\title{
Global Trends in Space Access and Utilization
}

\author{
Shamim A. Rahman* \\ NASA, Stennis Space Center, MS, 39529 \\ Nicholas S. Keim and Peter E. Zeender \\ The Johns Hopkins University, Chemical Propulsion Information Analysis Center, Columbia, MD, 21044
}

\begin{abstract}
In the not-so-distant past, space access and air/space technology superiority were within the purview of the U.S. and former Soviet Union's respective space agencies, both vying for global leadership in space exploitation. In more recent years, with the emergence of the European Space Agency (ESA) member countries and Asian countries joining the family of space-faring nations, it is truer now more than ever that space access and utilization has become a truly global enterprise. In fact, according to the Space Report 2007 , this enterprise is a $\$ 251-$ billion economy.

It is possible to gauge the vitality of worldwide efforts from open sources in today's transparent, media-based society. In particular, print and web broadcasters regularly report and catalog global space activities for defense and civil purposes. For the purposes of this paper, a representative catalog of missions is used to illustrate the nature of the emerging "globalization." This paper highlights global trends in terms of not only the providers of space access, but also the end-users for the various recently accomplished missions. With well over 50 launches per year, in recent years, the launch-log reveals a surprising percentage of "cooperative or co-dependent missions" where different agencies, countries, and/or commercial entities are so engaged presumably to the benefit of all who participate. Statistics are cited and used to show that recently over $40 \%$ of the 50 -plus missions involved multiple nations working collectively to deliver payloads to orbit. Observers, space policy professionals, and space agency leaders have eloquently proposed that it might require the combined resources and talents of multiple nations to advance human exploration goals beyond low earth orbit. This paper does not intend to offer new information with respect to whether international collaboration is necessary but to observe that, in continuing to monitor global trends, the results seem to support the thesis that a global interdependent effort with all its likely complexities is an increasingly viable and pragmatic option.
\end{abstract}

The discussion includes a breakdown of space missions into those of civil (scientific), military, and strictly commercial nature. It concludes that all three are robust components of a globally diversified portfolio of activities relying, essentially, on a common space industrial base and space infrastructure. As in other industries, the distribution of space industry assets and knowledge across countries and continents enables a diverse suite of options and arrangements, particularly in the areas of civil and commercial space utilization. A survey of several ongoing bilateral and multilateral space collaboration examples are provided to augment the observations regarding multinational work in space.

\footnotetext{
* Deputy Director, Engineering \& Test, NASA Stennis Space Center (SSC), MS, 39529, Associate Fellow.

Staff Engineer, CPIAC, 10630 Little Patuxent Pkwy., Suite 202, Senior Member.

$\$$ Deputy Director, CPIAC, 10630 Little Patuxent Pkwy., Suite 202, Senior Member.
} 


\section{INTRODUCTION}

Fifty years after the formal inception of the U.S. civil space program, it is appropriate to recount the prescient words of President Dwight D. Eisenhower leading up to the NASA Authorization Act of 1958. In his March 26 statement on "Introduction to Outer Space," the President stated to the country, and essentially to the world:

"(There are) many aspects of space and space technology ... which can be helpful to all people as the United States proceeds with its peaceful program in space science and exploration. Every person has the opportunity to share through understanding in the adventures which lie ahead."

"This statement [ ... I makes clear the opportunities which a developing space technology can provide to extend man's knowledge of the earth, the solar system, and the universe. These opportunities reinforce my conviction that we and other nations have a great responsibility to promote the peaceful use of space and to utilize the new knowledge obtainable from space science and technology for the benefit of all mankind."

There is much evidence today that Eisenhower's prognostication has borne out. While this former General is known for having coined the term Military-Industrial-Complex (MIC), he is less well known for his seminal contribution to the dawn of Human Space Flight and the civil space program.

Both aspects of President Eisenhower's forecast are at play in the twenty-first century. The purpose of this paper, however, is to show that the first aspect--civil and commercial space--might become the dominant aspect to influence and shape a worldwide space science industry devoted to meeting the evolving needs of humankind.

Once Sputnik deorbited in January 1958, more than 50 years ago, the U.S. and the former Soviet Union were investing heavily in civil space efforts, which some believe was a proxy investment toward military space ends. Following the superpowers' race to the moon, a period of retrenchment followed, which gave an opportunity for other parties to enter the space flight arena. Thus, the first significant multinational space collaboration efforts began in the form of the European Space Agency (ESA) in 1974- 35 years ago--with 6 nations and is now comprised of as many as 17 member nations.

The success of ESA following the success of the U.S. and former U.S.S.R. motivated Asian nations to institute long-term indigenous space technology efforts for both space access and utilization. Today, space access into low earth orbit (LEO) is available to virtually any nation willing to purchase a launch, and competitively offered by more than eight nations who are able to provide a launch vehicle for LEO payload delivery. Launch suppliers today include: U.S., Russia, Ukraine, China, Japan, India, ESA-member countries (France/Germany etc.), and several additional nations following closely behind with their own government-sponsored launch vehicles.

Today, worldwide launch rates are appreciable and sustained. Unbeknownst to most of the public, there is a major launch to earth orbit (ETO) essentially every week of the year. ETO launch missions may be placed into one of three categories: those for strictly military purposes, those for scientific purposes, and those for commercial needs; hereafter referred to as military, civil, and commercial space applications. It is worth noting that the mix of missions among the three major types is shifting toward an increased diversity of missions, sponsors, and providers. In looking closer at this mix, we are able to identify noteworthy trends about an emerging international industrial base for space products and services.

\section{SPACE LAUNCH DATABASE}

Industry observers are paying close attention to launch activity worldwide and the corresponding missions in order to accurately report their findings to a vibrant marketplace for space products and services. Figure 1 is an excerpt from a report by Futron Corp. provided as an example. ${ }^{2}$ This study indicated a fairly stable level of ETO launch activity in the beginning of the twenty-first century at sixty launches per year with approximately one-third being of the commercial (non-government) type. The actual number of launches is 55 for the years 2004 and 2005 .

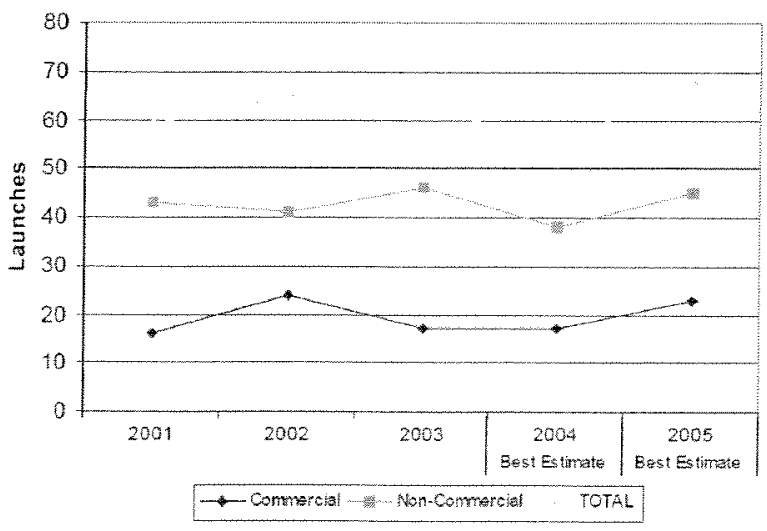

Figure 1. ETO Launches worldwide by type, 20012005 (reproduced with permission from 2004 report by Futron Corp, see Ref. 2). 
The Aerospace Corporation, a federally-funded, notfor-profit research and development center (FFRDC) in the U.S., also tracks launch activity and analyzes success rates of launch systems in detail, such as in the comprehensive Ref. 3 study, and their causes.

Notable examples of media observers also exist. For the purpose of this paper, multiple publicly sources were consulted, including Spaceflight Now's Launch Log and The Space Launch Report. ${ }^{45}$ The logs were compared for accuracy and formed the basis of the $\log$ used for this work, the CPIAC Launch Log. ${ }^{6}$ The data were further refined to include only successful launches of orbital satellites in order to reflect space utilization and not attempted utilization of space. An inspection of the launch log is informative in that it reflects top-level essential details of the mission such as the type of launch vehicle, the name of the payload(s), the location of the launch site, and the actual launch date/time, among other facts and figures. Whereas each launch event is a remarkable achievement in itself, the composite of information over multiple years can be quite instructive, for it gives insights into global trends in the space marketplace. The following two examples may illustrate the database's utility.

In the past decade it was expected that commercial technology needs would spur sustained demand for space launches for communications satellites. The launch $\log$ in Ref. 4 allows a multiyear review of such payloads since each mission payload is given. It was further expected that in the twenty-first century new launch providers and endusers would enter a market originally dominated in both supply and demand by the U.S. and the former Soviet Union in a bipolar twentieth century.

The database today reflects a global space marketplace, where end-users benefit by having a choice of launch providers at varying levels of risk and cost. Evidence of various types of collaborative arrangements between and among governments, international corporations, and private-public arrangements are found as well. As an anecdotal example, consider the comanifested Thai and Mexican payloads--launched on an Ariane vehicle (by ESA of Europe)--from the South American island site of Kourou in French Guiana (mission on 27 May 2006). Although at first glance this may seem to be an exceptional case, further review reveals many examples of bilateral/multilateral missions; such missions seem to be almost as common as the singlenation "indigenously conducted" missions.

The following discussion describes an "asis" state for global space access and makes specific observations by deriving information from 2004 to 2008 , the period for which the launch log was posted.
We begin by noting the various launch vehicles that comprise today's "operational global fleet," including their corresponding launch sites, and then note the types of payloads from various countries around the world that paid for access to space. Suborbital missions are excluded in this discussion since, for our purposes, "access to space" means achieving enough kinetic energy so as to sustain a payload for at least a few completed earth orbits, if not a mission duration of several years.

\section{SPACE LAUNCH INFRASTRUCTURE AND ACTIVITY}

ETO launch providers include governments and corporations located on three of the seven continents of the world (North America, Europe, and Asia), and are the product of aggressive R\&D from national space agencies. Both new and derivative models of launchers have evolved according to individual nation's space policies/strategies. Their respective launch sites are located around the globe-on land, coastal areas, and even on the ocean itself. A review of this diversity of capability is an integral part of understanding global trends.

Figure 2 shows the ETO launch vehicles employed for the missions given in the launch $\log$. This set of active launchers is surprisingly a modest fraction of the historical family of earth-to-orbit launchers referred to in Ref. 3 and described in more detail by Isakowitz in Ref. 7 . In order to facilitate comparison, the vehicles are shown approximately to scale, categorized by space powers, in approximate order of vehicle stack height. The Soviet space program derived launchers include the current versions known as Rokot, Proton, Zenit, Soyuz, Molniya, Tsyklon, Kosmos, Dnepr, Shtil', Volna, and Start-1. The current U.S. launcher fleet includes the Delta 2, the Medium, Intermediate, and Heavy-lift Delta 4, the Medium and Intermediate Atlas V, the Space Shuttle, Pegasus, Taurus, and Minotaur. A new and remarkable third group includes the operating launchers Ariane 5, Long March, H2A, M-5, PSLV, GSLV, and their variants, which have demonstrated payload delivery to ETO multiple times. Retired and sporadically used launchers are omitted; examples would include the U.S. Titan family of rockets, as well as earlier Delta, Atlas, Ariane, and other boosters such as the Soviet shuttle Buran.

In addition to the active launch vehicles (LV), a new suite of boosters is under development; examples include the Ares boosters, Falcon 1 and Falcon 9, Taurus 2, Angara, Vega, and others that have been openly promoted for ETO use. The demonstrated reliability of the new active launchers is imperfect but maturing. ${ }^{3}$ Nevertheless, the sheer 
number of variations of ETO-capable vehicles provides the launch customer with an array of options for payload delivery, covering a range of risk and cost tradeoffs.

Figure 3 illustrates the launch sites for the active launch vehicles, focusing on sites used during the period from 2004 to 2008 . The suborbital launch sites are omitted, unless an actual orbital launch occurred from that location, e.g., Wallops Flight Facility (WFF) on the Eastern seaboard of the U.S.

The workhorse launch sites exist within the continental U.S. and the former Soviet bloc countries. The latter will henceforth be referred to as Commonwealth of Independent States or CIS (postUSSR). In the U.S., Cape Canaveral Air Force Station (CCAFS) conducts many military launches and also hosts NASA's Kennedy Space Center (KSC) launch sites. Vandenberg Air Force Base (VAFB) continues to be active as well. The CIS' analogous sites are the Plesetsk and Baikonur cosmodromes, but the Dombarovsky site, the Svobodny site (limited use), and the Barents Sea (submarine) launch capabilities continue to serve as well. Commercial launch sites have also been added to the group, namely, Kwajalein--the Odyssey ocean launch platform-and Wallops Flight Facility, which was originally a suborbital launch site.

The Sea Launch Odyssey platform is an interesting case. The platform itself is owned and operated by Sea Launch, a multi-national corporation; it was converted from a Japanese oil platform into a floating launch site by a Norwegian company ${ }^{24}$ However, as Odyssey's home port is in California and Sea Launch operations are managed primarily by the Boeing Company, for the purposes of this paper Odyssey will be considered a U.S. launch site.

The emerging capabilities and activities for space access in non-US and non-CIS countries have increased greatly in the past two decades. Launch sites are a good indication of this, as the following seven sites that have been consistently active for the period of 2004-2008 of the launch log: China (Jiuqian, Taiyuan, Xichang), India (Sriharikota), Japan (Tanegashima, Uchinoura), and ESA (Kourou). Taken together one can see that the Northern Hemisphere is dotted with launch sites from the equator to the northern latitudes of the Barents Sea, and circumscribe the globe along the latitudes near the Tropic of Cancer. Coastal sites seem to be preferred, however, as China and Russia have shown, land launch sites are just as common. Several new launch sites for LEO access may become viable over the next decade as countries with nascent missile capabilities convert them to better performing larger vehicles for orbital payload delivery. Private launchers are also in development, though not addressed here. 

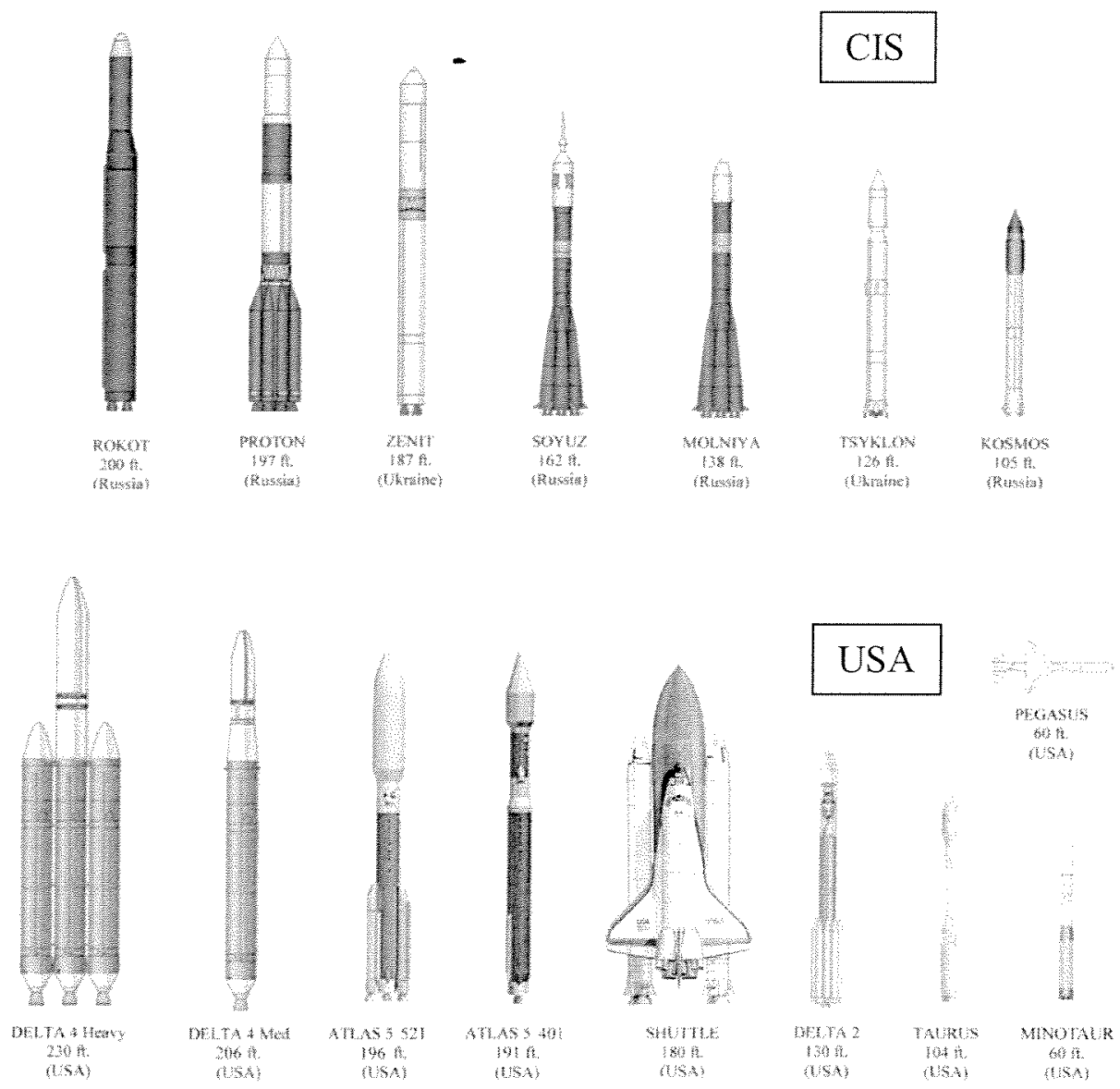

\section{Emerging}
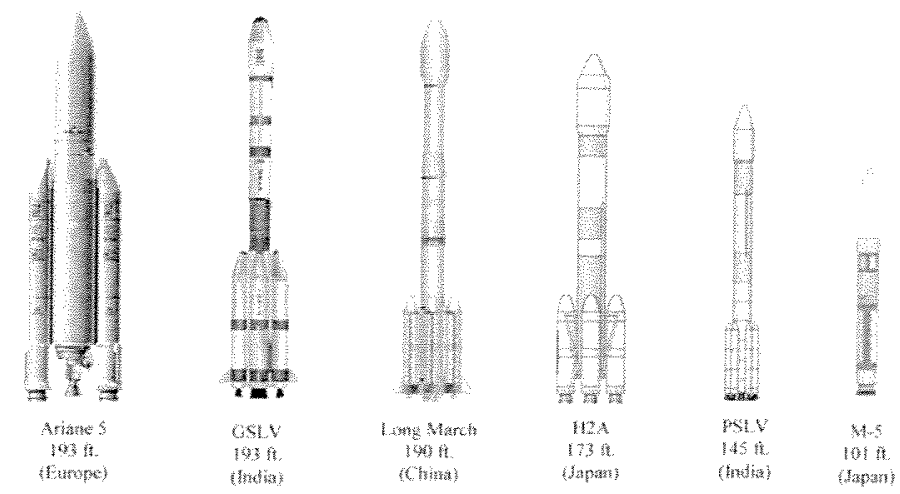

Figure 2. Depictions of most Earth-to-orbit launch vehicles used in recent years (scale is relative/approximate); various additional derivatives exist but are not shown for brevity. 


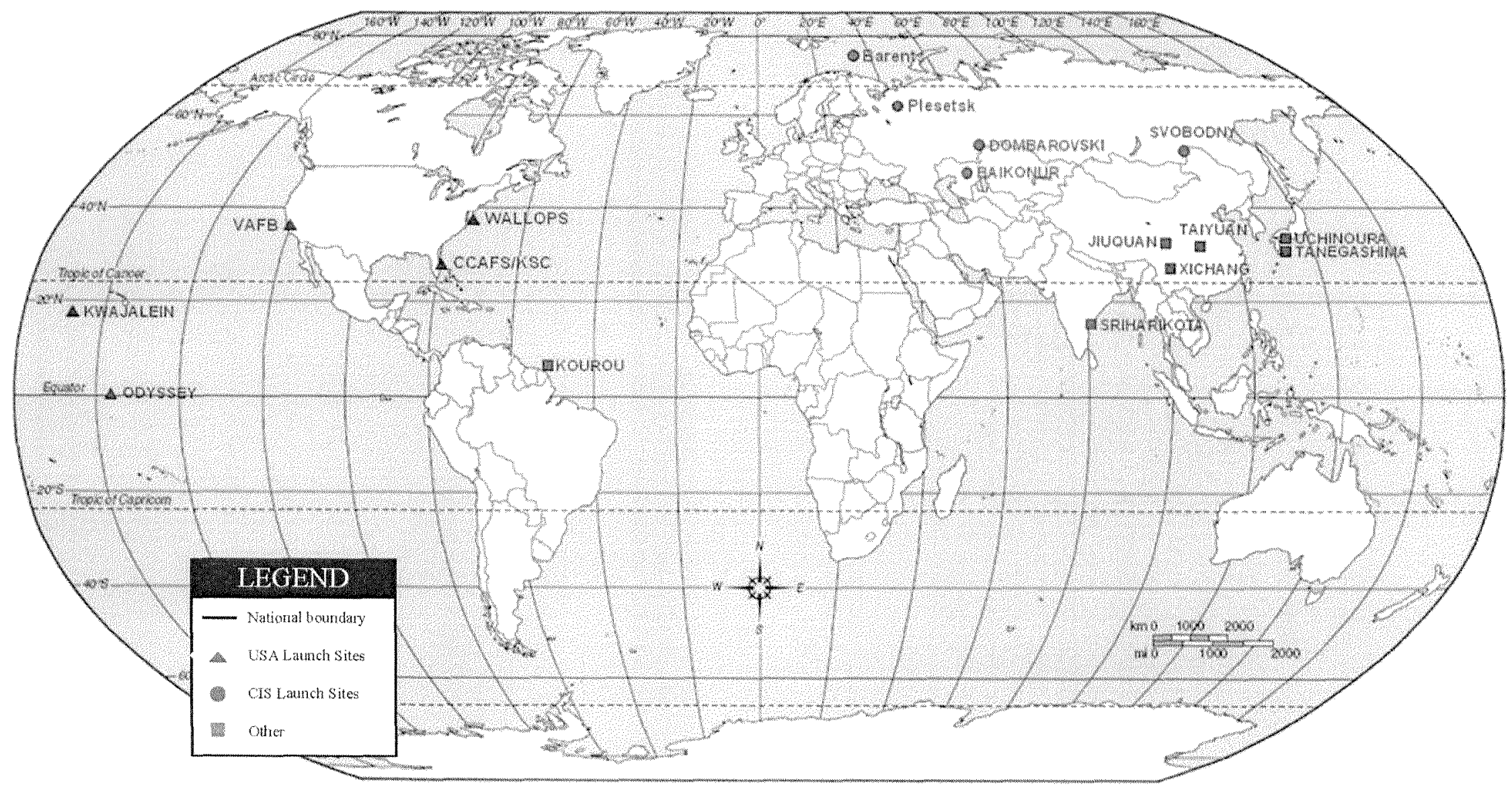

Figure 3. Launch sites employed for space access (from 2004 to 2008) by established worldwide providers of ETO launch services. 
Given the proliferation of ETO launch capability, a measure of worldwide space access is the number of mission conducted with these assets. Figure 4 compares the number of missions conducted by the U.S. and CIS with those of the newer spacefaring nations. There has been a steady rise of missions by the emerging space-faring nations. The combined activities of China, India, Japan, and ESA have led to 21 missions conducted in 2008, versus only 12 in 2004. At an annual global rate of approximately 50 to 65 missions per year, the fraction of missions conducted by emerging spacefaring nations has surged from 23 percent to 33 percent in a period of only 4 years. The numbers of payloads actually being lofted into orbit is greater than the number of missions/launches by a significant amount, as shown in Table 1 . This is due to payload co-manifesting (double or triple occupancy).

Unlike the data presented in Ref. 3, the recent, high success rates of newer space launch vehicles are attractive to prospective global users (commercial and government), making the newer launchers more competitive with the U.S. and CIS.

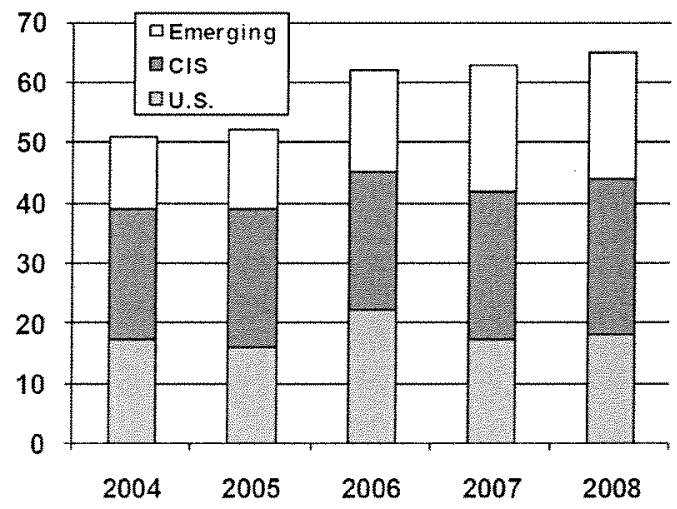

Figure 4. Worldwide space missions: Traditional versus Emerging ETO launches.

\begin{tabular}{|c|c|c|c|c|c|}
\hline \multicolumn{6}{|c|}{ Table 1. Missions and Payloads to ETO. } \\
\hline & 2004 & 2005 & 2006 & 2007 & 2008 \\
\hline $\begin{array}{c}\text { Space } \\
\text { Launches }\end{array}$ & 51 & 52 & 62 & 63 & 65 \\
\hline $\begin{array}{c}\text { Payloads } \\
\text { Lofted }\end{array}$ & 57 & 62 & 67 & 79 & 71 \\
\hline
\end{tabular}

Figure 5 presents data on worldwide space missions from 2004 to 2008 in terms of the amount of collaboration among nations, whether agencies or private-public entities. For the forthcoming discussion, collaboration among two or more space faring nations is meant to include the following types of bilateral or multilateral arrangements involving the launch pad, the LV, and the spacecraft $(\mathrm{S} / \mathrm{C})$ : a) Both $\mathrm{LV}$ and launch pad from one nation, and one or more S/C by other nation(s); b) both LV and S/C by a one nation, and the launch pad in and by another nation; or c) the launch pad of one nation and the LV and one or more S/C of another nation. Scenario C, though unusual, became possible upon the breakup of the Soviet Union (Kazakhstan of CIS having the launch pad), and applies also to Kourou, the primary provider of ESA's launch facilities. While there may be certain unusual permutations in the gray area (e.g., SeaLaunch Corp's use of a platform on the Pacific Ocean, and CIS submarine launches from Barents Sea), the above approach satisfies the analysis objectives of this work.

Collaborative "multi-party" missions account for more than one-third of all the combined missions from 2004 to 2008 . (The arrangements are varied and worthy of more detailed discussion, though beyond the scope of this paper). It is safe to assume that these collaborations are now considered more the "norm" than the exception. Since most military missions are performed within the purview of a single nation with vested national interest in mission success-- many scientific missions are this way also-most of the collaborative/cooperative missions tend to be a result of commercially-based motivations.

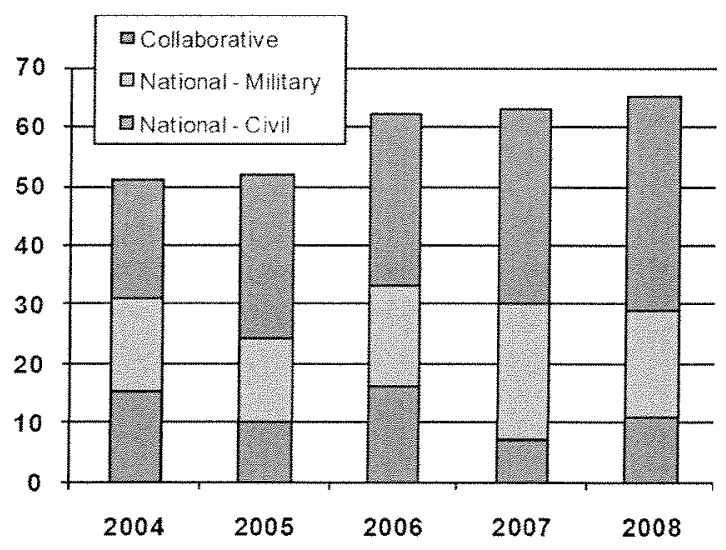

Figure 5. Collaborative missions requiring multination space infrastructure versus single-nation infrastructure for ETO payloads.

A representative example would be the following 2006 mission: a CIS Zenit booster, launched from the Pacific Odyssey ocean platform, carrying an American-built payload for Japan. Another example is the European Ariane 5 launcher delivering both a Thai and a Mexican satellite from its South America Kourou launch site. The involvement of 3 or 4 nations, with quite 
geographically dispersed assets, is not unusual of late. It would be interesting to develop a collaboration index specifying the degree of multilateralism involved in the missions (number of nations involved say), however this is deferred for future work.

A complementary metric to Figs. 4 and 5 is the comparison of ETO missions with a singlepayload manifest to those missions with a multipayload manifest, Fig. 6. According to the launchlog, single-occupancy payloads still dominate space launch manifests. There is, however, a trend of increasing multi-payload manifests. Figure 7 shows that the number of countries launching these types of missions is increasing.

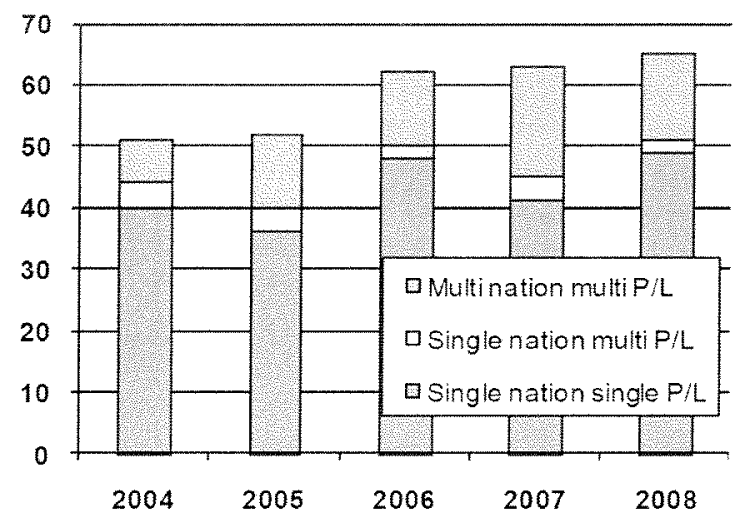

Figure 6. Comparison of space launches delivering single-payload versus co-manifested multi-nation payloads.

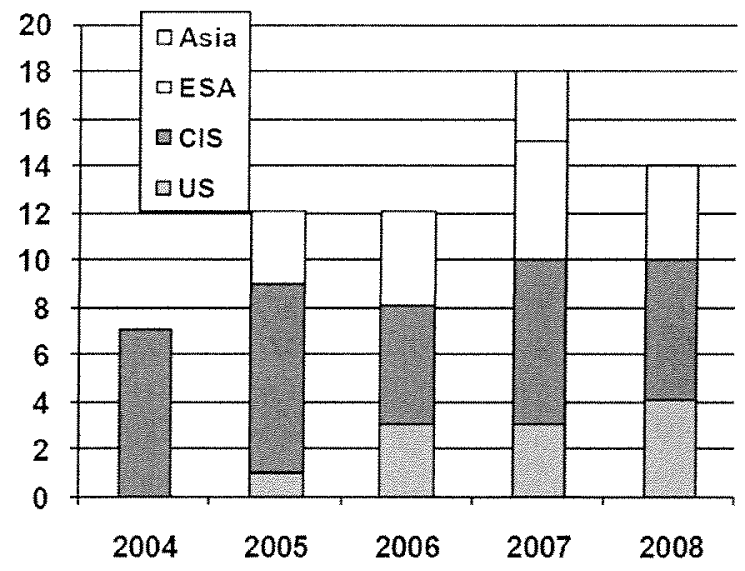

Figure 7. Space faring groups which have performed missions with co-manifested multination payloads.

The distribution of ETO launch vehicles and associated launch sites among the U.S., CIS, and emerging space-faring nations is illustrated in Fig. 8a and b. Despite a less diverse LV fleet, the latter group operates many launch sites.

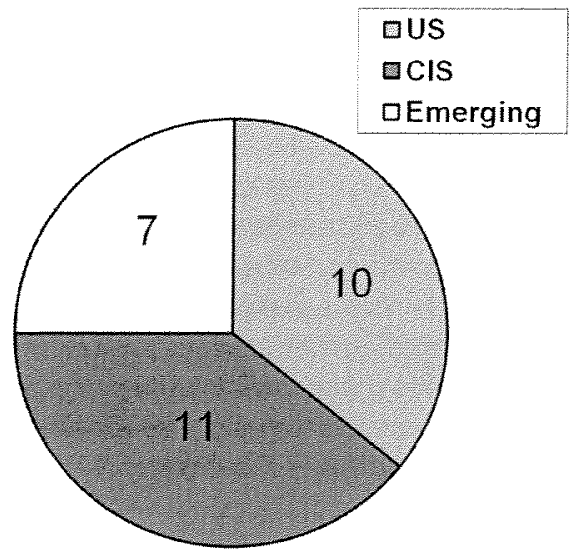

a) Launch Vehicle Types by source

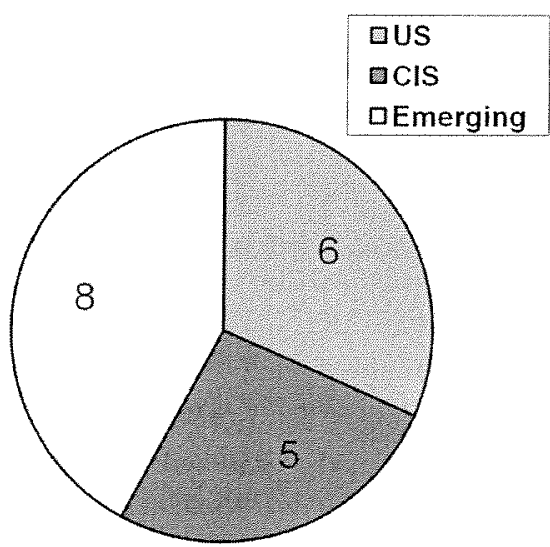

b) Launch Sites by source

Figure 8. Launch vehicle types (a) and launch sites (b) around the globe.

Table 2 summarizes information about launches/mission conducted by the U.S., CIS, and emerging space-faring nations, as reflected in Ref. 3 . The missions conducted by ESA are denoted separately in the table, though included under "emerging" capabilities in Figure 4. This grouping is somewhat subjective and debatable, given that ESA launches and missions date from the 1980s. For the purpose of this paper, non-U.S. and non-CIS nations are grouped together to better compare their space activity in relation to the two nations involved in the 1960 s space race. 


\begin{tabular}{|l|c|c|c|c|c|}
\hline \multicolumn{7}{|c|}{ Table 2. Worldwide Launches by Group. } \\
\hline & 2004 & 2005 & 2006 & 2007 & 2008 \\
\hline USA & 17 & 16 & 22 & 17 & 18 \\
\hline $\begin{array}{l}\text { CIS ("former } \\
\text { USSR") }\end{array}$ & 22 & 23 & 23 & 25 & 26 \\
\hline $\begin{array}{l}\text { ESA } \\
\text { ("Europe") }\end{array}$ & 3 & 5 & 5 & 6 & 6 \\
\hline $\begin{array}{l}\text { Asia (India, } \\
\text { China, } \\
\text { Japan) }\end{array}$ & 9 & 8 & 12 & 15 & 15 \\
\hline TOT = & $\mathbf{5 1}$ & $\mathbf{5 2}$ & $\mathbf{6 2}$ & $\mathbf{6 3}$ & $\mathbf{6 5}$ \\
\hline \begin{tabular}{l} 
Note: Emerging space faring nations are considered \\
here to be non-U.S. and non-CIS nations, namely \\
ESA group of countries-- India, China, and Japan. \\
\hline
\end{tabular}
\end{tabular}

An indication of interest in space utilization is possible by examining where the payloads are from internationally (Figure 9). This is estimated directly from the launch-log database of 2004-2008. Payloads from North America are the most numerous, with U.S. supplying 102 payloads, 7 from Canada and Mexico, and 5 from South America. The Asian countries, collectively, built or commissioned 92 payloads, while Europe built or commissioned 50 . The CIS payloads numbered 76, while Australia and African countries supplied 2 each.

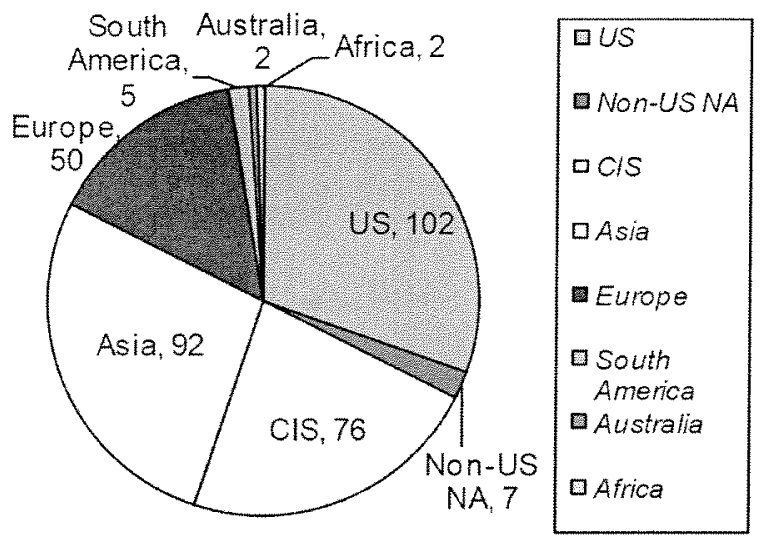

Figure 9. Worldwide interest in space utilization in terms of spacecrafts launched globally.

The space access marketplace is now a subject of great interest commercially and strategically for both the public and private sectors. ${ }^{8-}$

"The following sections of this paper highlight some trends found in this marketplace, as noted in open media sources.

\section{FACTORS INFLUENCING COLLABORATION}

If the advent of ballistic missiles ushered in the dawning of the Space Age, then it can be hypothesized that the globalization of space products and services (government and commercial) will be a signature of a new space era ahead. Despite setbacks due to the challenging nature of missions, the increase in worldwide space capability and infrastructure does not go unnoticed by governments, corporate enthusiasts, and the mass media; a representative example of each may be seen in Refs. 12,13 , and 14, respectively. Perspectives vary according to interests and are sometimes overly optimistic regarding potential synergies of transnational collaboration, and other times protectionist.

Perspectives aside, it is expedient to identify collaboration and cooperation ventures as either bilateral or multilateral, and consisting of government-to-government agreements, privatesector agreements across national borders, and combinations of governments and private companies as permissible by national authorities. The particulars of the arrangements are not within the scope of this paper; however, what is of interest here is the fact that a multitude of both public and private entities are indeed able to reach across national boundaries to serve a global client base.

\section{A. Economic Incentives for Cooperation}

Commercial activity spawns an interdependent approach to space access and space utilization. The amount of this activity is measured in the 2008 Space Report by the Space Foundation ${ }^{8}$ In particular, it identifies $\$ 251$ billion of global space revenue for 2007 worldwide. Remarkably, only $31 \%$ $-\$ 77$ billion--was attributable to government space budgets of the U.S. and other international government investments in space activity, which includes military space. The remaining $\$ 174$ billion was commercial revenue. The launch industry revenue portion is reported at $\$ 3$ billion annually, which seems a modest enabling investment by comparison.? The Space Foundation Index (SFI), an index of activity, has increased from a value of 100 in mid-2005, to 130 by year-end 2007, which is consistent with the trends in the previous section.

While commercially-developed and operated space transportation services are still limited, the users of such services are abundant and satellite builders have tapped into a strong satellite communications market. The 2008 Space Report gives the values of $\$ 65$ billion and $\$ 56$ billion for direct-to-home television service and global positioning (GPS) applications services, respectively. As long as there is a high demand for global satellite communications, the spacecraft constellations will require periodic replenishments and upgrades, thus 
sustaining a predictable market for launch providers to make the necessary constellation visits.

For the years 2004 to 2008, a large number of communications spacecraft were completed and delivered to orbit. The referenced launch-logs note that a variety of launch providers were utilized, ${ }^{4-6}$ including various U.S., CIS, and more recently, the emerging Asian nations' launchers.

It also is noteworthy that the commercial satellite business is historically rooted in the formation of Intelsat, an inter-governmental organization that was created to provide global satellite communications. In 2001, Intelsat was privatized into a multi-national corporation, and is one of the largest operators of satellites, with over 50 satellites in operation today. ${ }^{23}$

\section{B. Shared Vision for Space Utilization}

National space agencies typically maintain a strategic roadmap spanning a decade or two for their investments in non-military space. Non-U.S. national agencies, such as the European Union and Japan, maintain openly published roadmaps, often available on their Web sites. Conference proceedings openly document this type of information. ${ }^{10}$ For several years, the U.S. focused its civil space efforts on the 2005 Vision for Space Exploration (VSE). The U.S. VSE as released in 2005 envisioned a continuous human presence in space on-board the International Space Station (ISS), and also a lunar outpost in the 2020s. The EU intends to develop its own capabilities to send humans to orbit, and later to the moon, during the next two decades. Japan's space roadmap articulates a strong focus on societal benefits first and subsequently leads to goals and timeframes for human space access capability.

Such strategic plans are comparable or analogous in terms of certain goals or timeframes. For instance, in the specific case of Earth observation missions of remote sensing, in which all major national space agencies have an interest. A transparent internet-based media environment facilitates the exchange of information among national space agencies and both independent and collaborative planning for space. The Space 2008 Report summarizes some of this transnational collaboration and developing cooperation and collaboration is discussed in the Global Exploration Strategy Report, Framework for Coordination. ${ }^{14}$ The framework document-- summarizing the perspectives from space agencies of 14 nations--calls for the establishment of a formal voluntary non-binding mechanism by which space agencies can exchange information and coordinate activities and plans for their respective space exploration goals. Such a coordination mechanism would play a defining role in helping multiple space programs around the globe to move forward in concert and identify gaps, overlaps, and synergies along the way.

According to a NASA press release, "the framework document is an important step in an evolving process toward a comprehensive global approach to space exploration. Although the framework document is non-binding, its contents are consistent with ongoing bilateral and multilateral discussions that would lead to cooperative agreements for specific projects. In addition to NASA, representatives from civil space agencies in Australia, Canada, China, the European Union, France, Germany, Great Britain, India, Italy, Japan, Russia, the Republic of Korea and Ukraine participated in the Global Exploration Strategy discussions." 14 The member agencies include ASI (Italy), BNSC (UK), CNES (France), CNSA (China), CSA (Canada), CSIRO (Australia), DLR (Germany), ESA (Europe), ISRO (India), JAXA (Japan), KARI (South Korea), NASA (U.S.), NSAU (Ukraine), and Roscosmos (Russia). Many of the countries involved have developed an independent or inter-dependent (cooperative) viable space access infrastructure. Thus, at least both national economic and national strategic motives are expected to facilitate the globalization of space, and collaboration in particular. In Ref. 16, Hudiberg makes wellsupported observations after examining several decades of NASA's various types of collaboration agreements. Essentially, in categorizing hundreds of NASA collaborations over its entire history, Hudiberg finds that both policy and technology readiness can incentivize (or disincentivize) the U.S. space agency to collaborate across national borders. A marked decline in the number of collaborations was observed beyond the late $80 \mathrm{~s}$, which correlated strongly with increasing complexity or maturity of NASA projects where perhaps external relationships were perceived as making technology management more difficult. The ISS is a notable exception. Reference 17 reports on a special global space cooperation meeting (among high level government officials), where the desire for more integration among space-faring nations was discussed. Riess, Popp, and Ryzenko discuss space globalization at a tactical level with programmatic case studies, where all argue in favor of global space cooperation and knowledge sharing. ${ }^{18-20}$

Additional factors that may drive collaboration include the collateral benefits of space technology that accrue toward military and political goals, however, these are excluded from the scope of this paper and may be studied in the future. Instead, the remaining discussion presents some selected 
examples of transnational space collaboration in order to better appreciate the many varieties of collaborative relationships in space ventures. The following examples are taken from mass media reports and may be broadly categorized into one of two types of collaboration (among space agencies): either bilateral or multi-lateral. The intent is simply to survey, rather than analyze, the examples as representative of demonstrated successes in the international space arena, and therefore templates for future ventures.

Bilateral space collaboration often occurs among nations that are otherwise expected to be competitors in political arenas and/or are geographically and culturally separated. For instance:

- China and Brazil: Earth Resources Satellites (at least three spacecraft), known as CBERS, since 1988.

- China and France: Sino-French Joint Commission on Space Cooperation, since 2003.

- Russia and China: The "Cooperative Agreement between the China National Space Administration and the Russian Space Agency on joint Chinese-Russian exploration of Mars," in March 2007.

- U.S. and India: Memorandum of Understanding (MoU) of 2006 regarding US instruments to be carried on Indian robotic lunar spacecraft Chandrayaan-1; this mission just completed in 2009.

- Russia and EU: Agreement in 2008 to cooperate on a future manned vessel for transporting astronauts to the moon.

- Russia and U.S.: Joint venture known as International Launch Services (ILS),providing either U.S. (Atlas) or Russian (Proton) launch vehicles, since 1995.

Multi-lateral collaboration is as varied in purpose as it is in participation, as evident below:

- Sixteen nations (12 European, 2 American, 1 Asian, and Russia): Working together to build and operate the U.S.-led International Space Station, over the past two decades.

- Three nations: Corporate collaboration among U.S., Russian, and Norwegian companies to provide equatorial-latitude based launches, since 1995.

- Multi-national Corporation: Corporations in which operations are spread across national boundaries. Examples such as Intelsat deploying and operating a global network of spacecraft for worldwide instant communications needs, since 1964.
- Twelve (national) space agencies: Selected member subgroup of the United Nations Charter on Cooperation to Achieve the Coordinated Use of Space (UNCOPUOS) facilities in the event of natural or technological disasters, since 2000 ; there are a total of 69 nation members of UNCOPUOS.

- Eight countries (two North American, four European, and three Asian): Signatories to the recent International Lunar Exploration Agreement in 2008.

- Fourteen countries (two North American, three Asian, six European, two CIS, and Australia): Signatories to The Global Exploration Strategy Framework, released in 2008.

- Eight countries (Asiatic): Per Ref. 10, "In October 2005, the representatives of China, Bangladesh, Indonesia, Iran, Mongolia, Pakistan, Peru and Thailand signed the Asia-Pacific Space Cooperation Organization (APSCO) Convention in Beijing, and in June 2006 Turkey signed the Convention as well."

The examples are not intended to be comprehensive; they simply illustrate a variety of goals, objectives, participants, and interests--whether the goal is to deliver hardware to orbit or to codevelop policies and plans. It is possible to take this discussion much further, by analyzing the entire set of known transnational collaborative agreements in terms of their strengths/weaknesses and technical/financial and strategic/tactical aspects. This is reserved for follow-up work to possibly prognosticate and/or propose the shape of future global space partnerships.

A recent workshop convened several national experts to further delve into space cooperation and competition. ${ }^{21}$ Participants included government, academia, and industry representatives attached to or invited by the National Research Council. Special attention was given to governmental space cooperation and competition during and after the cold war and the lessons learned from that history. A discussion by Launius concludes that "...cooperative space endeavors have been richly rewarding and overwhelmingly useful..." amidst the many technical, management, and political challenges that were faced. ${ }^{21}$, Section 1 Keynote Additionally, it was pointed out that 50 years of valuable experience in conducting global space cooperation has accrued to serve as a strong foundation for further ventures.

\section{CONCLUSION}

The socio-techno-political climate for an exponentially expanding global and industrial space 
age may depend first upon the national strategic and economic interests of prospective participants. Fortunately, the enabling technological infrastructure for future collaboration appears to be maturing rapidly and strengthening in this early part of the twenty-first century. At least eight countries provide ETO space launch capability and/or satellite manufacturing capability to payload customers, through either government-sponsored missions or privately marketed launch services. The community of scientific and business payload/spacecraft developers is, therefore, likely to be well served in the foreseeable future.

More ambitious and long-term endeavors for both robotic and human space flight will rest on government resources, yet here too, there appear to be more options for government customers in terms of suitable launch vehicles and launch sites around the world. National governments and their respective space agencies are making concerted efforts to leverage global experience and knowledge in exploring space and exploiting technology to serve their constituent's needs on Earth. Many open forums and conferences now exist to facilitate these efforts through technical interchange and frequently lead to business relationships thereafter.

Further examination of the space services marketplace (access and utilization) is possible in terms of the success and failure of cooperatives, the pace of development of new space access capability (either private or governmental), or the operations and sustainment of such capability, where multiple geographically-dispersed parties are involved. The maturation of the space sector is occurring at a rapid pace with the many actors now involved.

In closing, the following phrase from a 2008 commentary essay in a U.S. trade publication says it well: "...there is no doubt that the internationalization of space is enjoying a period of ascendancy." 22

\section{ACKNOWLEDGEMENTS}

The authors would like to thank the following reviewers for their assistance in honing the thoughts and discussion of this paper: Dr. J. Emdee of The Aerospace Corp. and Mr. Steve Hanna of NASA Marshall Space Flight Center.

\section{REFERENCES}

The references below are cited in the paper, and most may be obtained through AIAA services.
1 The United States, President's Science Advisory Committee. Introduction to outer space U.S. Government Printing Office, Washington D.C. 1958

2 "The Space Launch Industry Recent Trends and Near-Term Outlook," Futron Corp. report, October 21, 2004.

$<\mathrm{http}: / /$ www.futron.com/pdf/resource_center/white_p apers/Launch Industry_WP_Part_3.pdf $>$

3 Tomei, E. J., and Chang, I-S., "51 Years of Space Launches and Failure," Paper No. IAC-09-D1.5.1, $60^{\text {th }}$ International Astronautical Congress, Korea, 1216 October, 2009.

4 "Worldwide Launch Log." Spaceflight Now. 1 Feb. 2009 ,

$<$ http://www.spaceflightnow.com/tracking/launchlog. html $>$.

5 "The Space Launch Report." Ed Kyle. 3 Mar. 2009, <http://www.spacelaunchreport.com>.

6 "CPIAC Launch Log." The Chemical Propulsion Information Analysis Center, 26 Aug. 2009, < http:/www.cpiac.jhu.edu/templates/cpiacTemplate/la unchlogs $>$.

${ }^{7}$ Isakowitz, S. J., Hopkins, J. P., Jr., and J. B. Hopkins, International Reference Guide to Space Launch Systems, 5th ed. (AIAA Publications, Washington, D.C., 2004).

8 "The Space Report 2008 - Executive Summary," published by Space Foundation, 2008, pp. 1-12.

9 "State of the Satellite Industry Report," Futron Corp. briefing, sponsored by Satellite Industries Association, dated June 2008

10 "Session on International Collaboration and Global Exploration," Proceedings of $3^{\text {rd }}$ Space Exploration Conference \& Exhibit, Denver, USA, Feb. 26-28, 2008.

${ }^{11}$ Griffin, M. D., "Remarks on International Cooperation," Parliamentary Group on Space, French National Assembly, France, Paris, June 5, 2008.

12 "Overview," Virgin Galactic. 2008, Aug. 10, 2008, $<$ http:/www.virgingalactic.com/htmlsite/overview.ph $\mathrm{p}>$.

${ }^{13}$ Kaufman, M., "U.S. Finds It's Getting Crowded Out There." The Washington Post, July 9, 2008: pp. A01.

14 "The Global Exploration Strategy: The Framework for Coordination," report released May 31, 2007, 25 $\mathrm{pp}$.

15 "NASA, 13 Space Agencies Release Exploration Strategy Framework," NASA Press Release, 31 May 2007. 
${ }^{16}$ Hudiburg, J., "Techno-Political Space Cooperation: a Model for Explaining NASA's Record of International Cooperation," IAC-03-IAA.3.2.06, 54th International Astronautical Congress of the International Astronautical Federation, Bremen, Sep. 29-31, 2003.

${ }^{17}$ Girard, T., and Sabathier, V., "Space Exploration and International Cooperation," IAC-04-

IAA.5.13.P.06, 55th International Astronautical Congress of the International Astronautical Federation, Vancouver, Canada, Oct. 4-8, 2004.

${ }^{18}$ Riess, C., "Towards a New Strategic Setting of International Space Policy," IAC-04-IAA.5.13.3.06, 55th International Astronautical Congress of the International Astronautical Federation, Vancouver, Canada, Oct. 4-8, 2004.

${ }^{19}$ Popp, M., and Parsley, R. C. "International Cooperation in Space Launch Propulsion," AIAA2003-2906, AIAA International Air and Space Symposium and Exposition: The Next 100 Years, Dayton, Ohio, July 14-17, 2003.

${ }^{20}$ Ryzenko, J., "Learning from ISS, Thinking of Moon and Mars International Cooperation in Human Space Exploration," IAC-04-IAA.5.13.P.08, 55th International Astronautical Congress of the International Astronautical Federation, Vancouver, Canada, Oct. 4-8, 2004.

21 "Approaches to Future Space Cooperation and Competition in a Globalizing World - Summary of a Workshop," National Research Council Report (Rapporteur J. V. Zimmerman), Workshop held in Irvine, CA., Nov. 18-20, 2008.

${ }^{22}$ Grey, J., "Commentary - The New Global Space Scene," Aerospace America, Vol. 46, No. 2, Feb. 2008.

23 “About Us," Intelsat. 2009. Nov. 2, 2009.<http:/ www.intelsat.com/about-us/>.

24 "Facilities," Sea Launch. 2009. Nov. 2, 2009.

$<$ http://www.sea-launch.com/slfacilities.htm>. 
The public reporting burden for this collection of information is estimated to average 1 hour per response, including the time for reviewing instructions, searching existing data sources, gathering and maintaining the data needed, and completing and reviewing the collection of information. Send comments regarding this burden estimate or

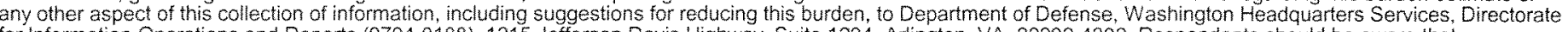
for Information Operations and Reports (0704-0188), 1215 Jefferson Davis Highway, Suite 1204, Arlington, VA 22202-4302. Respondents should be aware that

nowithstanding any other provision of law, no person shall be subject to any penaly for failing to comply with a collection of information if it does not display a currently valid OMB control number.

PLEASE DO NOT RETURN YOUR FORM TO THE ABOVE ADDRESS
1. REPORT DATE (DD-MM-YYYY)
2. REPORT TYPE
01-04-2010
Technical
3. DATES COVERED (From - To)
January 2009 - November 2009

4. TITLE AND SUBTITLE

Global Trends in Space Access and Utilization

5a. CONTRACT NUMBER

Collaboration work; no contract needed.

\section{5b. GRANT NUMBER}

None

5c. PROGRAM ELEMENT NUMBER

Not Applicable

\section{AUTHOR(S)}

Shamim A. Rahman, NASA Stennis Space Center, MS.

Nick Keim, Chem. Propulsion Info. \& Analysis Center, Johns Hopkins, MD

Pete Zeender, Chem. Propulsion Info. \& Analysis Center, Johns Hopkins, MD

5d. PROJECT NUMBER

Not Applicable

\section{5e. TASK NUMBER}

Not Applicable

5f. WORK UNIT NUMBER

Not Applicable

\section{PERFORMING ORGANIZATION NAME(S) AND ADDRESS(ES)}

NASA, John C. Stennis Space Center, MS.,

8. PERFORMING ORGANIZATION REPORT NUMBER and,

Chemical Propulsion Information \& Analysis Center, Johns Hopkins Univ., MD.

(www.cpiac.jhu.edu)

None.

9. SPONSORING/MONITORING AGENCY NAME(S) AND ADDRESS(ES)

10. SPONSORING/MONITOR'S ACRONYM(S)

NASA Stennis Space Center.

11. SPONSORING/MONITORING

REPORT NUMBER

\section{DISTRIBUTION/AVAILABILITY STATEMENT}

Unclassified.

\section{SUPPLEMENTARY NOTES}

Work was done in collaboration between NASA SSC author, and JHU CPIAC authors. CPIAC mission is to perform or support analysis for the nation's propulsion community. (see www.cpiac.jhu.edu for details of services.)

\section{ABSTRACT}

In the not-so-distant past, space access and air/space technology superiority were within the purview of the U.S. and former Soviet Union's respective space agencies, both vying for global leadership in space exploitation. In more recent years, with the emergence of the European Space Agency (ESA) member countries and Asian countries joining the family of space-faring nations, it is truer now more than ever that space access and utilization has become a truly global enterprise. In fact, according to the Space Report 2007 , this enterprise is a $\$ 251$-billion economy. This paper highlights global trends in terms of not only the providers of space access, but also the end-users for the various recently accomplished missions. With well over 50 launches per year, in recent years, the launch-log reveals a surprising percentage of "cooperative or co-dependent missions" where different agencies, countries, and/or commercial entities are so engaged presumably to the benefit of all who participate. The discussion includes a breakdown of space missions into those of civil (scientific), military, and strictly commercial nature. It concludes that all three are robust components of a globally diversified portfolio of activities relying, essentially, on a common space industrial base and space infrastructure.

\section{SUBJECT TERMS}

Launch vehicles, space access, space infrastructure.

\begin{tabular}{|c|c|c|c|}
\hline 16. SECURITY CLASSIFICATION OF: \\
\hline a. REPORT & b. ABSTRACT & c. THIS PAGE \\
$U$ & $U$ & $U$ \\
\hline
\end{tabular}

\section{LIMITATION OF} ABSTRACT

UU

\section{NUMBER 19b. NAME OF RESPONSIBLE PERSON}

\begin{tabular}{l|l} 
PF & Dr. Shamim A. Rahman
\end{tabular}

19b. TELEPHONE NUMBER (Include area code)
14
(228) 688-2610 